\title{
ERP in Indian SME's: A Post Implementation Study of the Underlying Critical Success Factors
}

\author{
Parijat Upadhyay (Corresponding Author) \\ International School of Business and Media, EN-22, Sector-V, \\ Saltlake City, Kolkata-700091, India.
}

Tel: +91 33 66131645. Email: parijat.upadhyay@gmail.com

Pranab K Dan,

West Bengal University of Technology, BF-142, Sector I,

Salt Lake City, Kolkata - 700064, West Bengal, India.

Tel: +919830251805.dan1pk@hotmail.com

\begin{abstract}
Over the past year, the global economic crisis has put the spotlight on many business organizations of any size. With India not being spared of the impact, large establishments have attempted to tackle this crisis in their own ways. Amid all this, SME's are increasingly being brought into focus on account of their huge growth potential.

The SME sector in India, which contributes almost half of India's GDP and is home to a slew of business opportunities. SME's can carve out value-adding niches for themselves and play an important role at a time when global corporations revisit their established supply and sourcing patterns as a response to the changed business climate.

In the need to remain competitive, they are looking at supply chain areas and Enterprise Resource Planning (ERP) solutions seemed to have emerged as a ready made solutions to many SME's.Therefore, it's of particular interest to analyze the operating implementations, in order to identify the success cases, the nature and measure of the benefits obtained and the context and project-related factors which can influence the chances of a positive outcome. The research presented here was specifically targeted to the SME's which already completed the process of adopting an ERP system to bring out the underlying factors which can prove decisive for success and to propose a framework that seem to guide This study is based on feedback that has been obtained from 150+ responded who were from various forms of industries, which are essentially SME in nature.
\end{abstract}

Keywords: ERP, SME, vendor selection, communication, support, cost 


\section{Introduction}

The Indian small and medium businesses (SMBs) are eyeing enterprise technology solutions for their businesses in these days of changing business scenario. Although this shift has been shift has been gradual but it is picking up as Indian SMBs are now competing globally and they need to gain a competitive edge to win amidst global competition. Technology provides them this edge. For example, the recent IBM and Info-Tech Research Group highlights that $63 \%$ of Indian IT firms have completed a retrofit of existing server rooms to increase energy efficiency, or have a pilot underway. This clearly demonstrates that SMBs in India look at technology as an enabler and are ready to acquire technology to gain advantage. Companies are under pressure to act quickly in response to economic uncertainty and are under more pressure than ever to maximize the returns on their investments while improving service, at lower risk and reduced budgets. Customers across the board are looking at efficient management of IT infrastructure and are investing in emerging technologies like virtualization, consolidation, data de-duplication, etc. As operational costs and complexity reach unsustainable levels, companies need to look for innovative ways to evolve their infrastructure. Research and survey by leading IT vendors clearly points out that SMBs are spending despite the slowdown, across sectors. The need for technology solutions is not only confined to Tier 1 cities in India( like the metros and other big cities) but are also being felt business organizations operating from Tier II and Tier III cities also. As a result of this global players like IBM have been expanding their geographic coverage beyond India’s Tier-1 cities and enhancing their partner relationship to address more of this mid market opportunity.

\section{Background of the Study}

Saying that information technology (IT) is a business enabler is passé today. The scale and demands from IT infrastructure have increased significantly over the last decade.

For many organizations, the IT infrastructure serves as a strategic asset. A company can unlock the potential of this investment by aligning business needs with IT infrastructure. Interestingly, a recent study( Feb.2009)shows that 60-70 per cent of every SMB's IT budget gets pumped into running and maintaining a current infrastructure-as a result of which, a mere 30 - 40 per cent of expenses fuel the requirements of fresh IT requirements and projects.

While some SMB's look at IT budgets as an additional expense, IT infrastructure helps improve productivity, optimize business through effective resource deployment and in manufacturing through reduced cost of production.

The survey report also estimates that IT services spend in the domestic market are estimated to grow to INR 24,158 core in 2010. Sectors like BFSI, telecom, media and manufacturing are investing heavily in corporate IT infrastructure. Even several government departments have also made significant investments in IT infrastructure. To keep pace with changes in business scenario, the SMB's aim at reducing cost, try to increase revenue by empowering your own sales and support teams, Control and simplify business processes via workflow, lay an architectural framework that will provide the enterprise with greater agility and overall try 
and ensure sustainability of their business. In such a scenario Enterprise Business solutions have emerged as a ready solution to business organizations of any magnitude. Lured by seer magnitude of the SME sector in any country and particularly in a country like India, many ERP vendors have been moving their attention toward SME's by offering simplified and cheaper solutions from both the organizational and technological points of view,pre-configured systems based on best-practices at a fraction of the cost originally required and promising implementation times of 60 days. In spite of such promises, there is not a general agreement on the effectiveness of such systems. As a result, the current ERP systems adoption rate in SME's is still low. Such a scenario raises some serious questions: Are SME's informational needs different from that of large companies? Is it possible to identify a relationship between organizational change and ERP adoption in companies of different size? Can certain factors be identified that can be considered critical in context to SME's on account of their peculiarities? (Ravarini et.al.2000, Schubert et. al., 2004).

ERP system implementation issues have been subjected to substantial research( categorized bibliographies are in Esteves \& Pastor Esteves and Pastor.2001,and Moller et al.,2004 that, under various theoretical perspectives, dealt with aspects like: characteristics, adoption and implementation processes( Nandhakumar et.al.,2004,Butler and Pyke,2003 ), favourable elements in the context, project design and/or execution(Butler and Pyke,2003) organisational impacts(Westrup and Knight,2000),forecasting of the probability of success(Magnusson et. al.,2004),extension towards e-commerce(Schubert,2003,Kemppainen,2004).With more and more ERP vendors targeting SME segment, researchers in many countries have tried to bring out the differences in comparison to large companies in terms of pre-conditions, project behaviours, result achieved[Costa et.al.,2006,Compagno et. al.,2004,Caruso et. al.,2003,Tagliavini et al.,2002,Equey et al.,2004,El Amrani et al.,2003,Beck et al.,2002,Chan,1999) asserts that many SME's either do not have sufficient resources or are not willing to commit a huge fraction of their resources due to the long implementation times and high fees associated with ERP implementation. The resource scarcity, the lack of strategic planning of information systems (IS)(Levy et al.,2000), the limited expertise in IT (Levy et al.,2000) and also the opportunity to adopt a process-oriented view of the business are among the factors that strongly influence, either positively or negatively, ERP adoption by SME's. Thus it is necessary to find out alternative solutions providing the ERP capabilities at an affordable price, including implementation costs(Rao,2000).

Through a detailed literature review, a set of indicators are identified as variables which can prove to be critical and could influence the ERP adoption process to be point of being labelled a success or failure. These indicators have been tested on the field through an empirical study.

\section{Research Objectives and Methodology}

Certain factors have been found to be critical in context to implementation of IT projects. This study have tried to identify certain Critical Success Factors (CSFs) firms should focus on to be successful. Critical success factors refer to "the limited number of areas in which satisfactory results will ensure successful competitive performance for the individual, 
department, or organization”. Identifying CSF's is important as it allows firms to focus their efforts on building their system to meet those CSF's and it even allow firms to decide if they have the capability to build the requirements necessary to meet CSF's.

The different CSFs were identified after doing an extensive literature study and from the questionnaire survey of organizations that have gone through the implementation process. The content validity of these constructs was tentatively established by extensive review with top executives and other stakeholders. Some items were removed from the construct if their removal results in an increase in the reliability estimates, however care was taken to ensure the validity of the measures is not threatened by the removal of a key conceptual element.

The CSFs identified can be listed as follows:The support of higher authorities throughout the entire implementation phase,the top management being project champion thus driving the implementation in case of obstacles,the implementation required minimum customization and BPR,the competency level of implementation team,the proper project management,effective communication amongst the team members during the process, the clearly defined goals and objectives,acceptance of changes brought about by the implementation of the new system,the users were subjected to adequate training and education regarding usage of the new system,adequate user involvement and participation during the implementation phase,adequate vendor support throughout the implementation phase, the participation and contribution of external consultant,compatibility of the new system with the existing technical infrastructure,the composition and leadership of the project team,proper selection of package,scope of implementation,adequate features of scalability in the package chosen and implemented,user friendliness of the implementation process and cost of the package.

\subsection{Survey Methodology}

Invitations to participate in the survey requested responses from implementers of ERP packages who have basically worked for small and medium scale enterprises based in India and have been associated with the implementation process for their respective organisation. The researchers therefore created items to measure the constructs, and used five-point multi-item, Liker-type scales for each item where " 1 " meant "Strongly Disagree" and "5" meant "Strongly Agree.” Questionnaire survey method was selected following the previous study to evaluate the importance of the CSFs that have been found through literature review. A postal survey questionnaire was used as the research instrument. The questionnaire is focused on the importance of critical success factors that clarified from literature review. It identifies the respondents' perception of the importance of CSFs in the ERP implementation process. For each of these factors, a number of elements or statements were formulated through the definition and description of each one in the literature.

\subsection{Data collection procedures}

The target respondent in each firm was the chief information officer (CIO), the director of MIS, IT Manager or any person responsible for ERP System since they are directly involved in ERP system. Overall, 160 responses were obtained for analysis. A wide variety of industries were represented in the responses. The companies classified by industry type title are described as shown in Tables 1. 
Table-1 Industry Number of Companies

\begin{tabular}{|c|c|}
\hline Education & 7 \\
\hline Insurance & 4 \\
\hline Retail & 8 \\
\hline High Technology & 10 \\
\hline Financial Services & 5 \\
\hline Manufacturing & 44 \\
\hline Utilities & 6 \\
\hline Healthcare & 7 \\
\hline Government & 2 \\
\hline Telecommunication & 5 \\
\hline Total & 98 \\
\hline
\end{tabular}

Table showing the number and types of participative business organizations in the survey

\subsection{Pilot Study}

Seven experienced client project managers pilot tested the survey. The researcher requested that the pilot subjects identify and suggest improvements for any omission, error, or inconsistency in the survey. All seven of the pilot participants completed the survey in the presence of the investigator. The pilot test resulted in several small revisions to the primary instrument that included rewording of a few items, the addition of a few demographic questions, and alterations to the instructions to make them easier to understand. No scaled item was dropped or added as a result of the pilot study.

\section{Data Analysis and Discussion}

Data were collected from the users of the leading ERP vendors: SAP, Oracle, Microsoft and some local vendors who have developed customised ERP packages.

The respondents came from manufacturing (44\%), education and training (7\%), high technology (10\%), telecommunications (5\%), retail (8\%) and a variety of other industries. They were also fairly well educated with $87 \%$ having a four-year or higher college degree. They had about $5+$ years of experience in their current area with their current employer.

The sample size that was obtained by the researcher was 160 , so Kolmogorov-Smirnov's test was conducted to test for data normality. The significance values of all the variables were less than .05 , thus indicating the data were not normally distributed, but both the Skewness \& Kurtosis are in the acceptable range $( \pm 1.0)$. Using the rule of thumb cited in many statistical 
books for social science, this variable (Tangible) is close to normality.

With the objective of establishing the reliability of the data collected and that of the study, Cronbach's alpha of the data pertaining to the factors was calculated. The value was found to be 0.842 and hence this data set can also be considered to be reliable.

Table 2 presents the means and standard deviations for the 16 CSFs in descending order of importance (5=Strong agree, 4=Agree, 3= neither Agree nor Disagree, 2=Disagree and $1=$ Strong Disagree). User Knowledge was viewed as most important by of our executives. Likewise, among the top ten important Cuss are: project team competence, Goal \& Objective, Improve Work Efficiency, Top Management Support, project management, project champion, Project Team Competency, Infrastructure, ERP Importance, and User Training. Surprisingly, use of consultants and use of vendors' tools did not appear to be very important in the implementation process for these companies.

Table 2. Mean rankings of CSFs by degree of Importance in ERP implementation

\begin{tabular}{|l|c|c|}
\hline Factors & Mean & Std. Deviation \\
\hline User Knowledge & 4.42 & 0.668 \\
\hline Goal \& Objective & 4.38 & 0.642 \\
\hline Infrastructure & 4.23 & 0.625 \\
\hline Improve Work Efficiency & 4.19 & 0.617 \\
\hline Project Champion & 4.17 & 0.67 \\
\hline Top Management Support & 4.14 & 0.751 \\
\hline Project Team Competency & 4.14 & 0.76 \\
\hline Scalability \& Scope & 4.11 & 0.52 \\
\hline Project Management & & \\
& 4.06 & 0.605 \\
\hline ERP Importance & 4.03 & 0.555 \\
\hline User Training & 4.03 & 0.66 \\
\hline External consultant & 3.96 & 0.529 \\
\hline $\begin{array}{l}\text { Interdepartmental } \\
\text { Communication }\end{array}$ & 3.95 & 0.838 \\
\hline Package Selection & 3.81 & 0.865 \\
\hline Sponsor & 3.69 & 0.948 \\
\hline Vendor Support & 3.64 & 0.936 \\
\hline
\end{tabular}

Table showing the mean and standard deviations of the various Critical Success Factors(CSF) considered in the study

Harman's one factor test was performed to detect common method variance, a potential problem when respondents might be inclined to give socially acceptable answers, the same respondent answers two or more constructs in a self-reported survey, and an attempt is made 
to establish a correlation between them. All the variables in the study were entered into an exploratory factor analysis. Eight factors total accounted for $80 \%$ of the variance. The researchers have considered factors having Eigen value greater than one. Thus we have extracted 7 factors and the first two factors are the major factors out of 7 factors contributing $31 \%$ of the total variance.

Table 3: Total Variance Explained

\begin{tabular}{|r|l|r|r|}
\hline Component & \multicolumn{1}{|c|}{ CSF } & \multicolumn{1}{c|}{$\begin{array}{c}\text { \% of } \\
\text { Variance }\end{array}$} & $\begin{array}{c}\text { Cumulative } \\
\%\end{array}$ \\
\hline 1 & $\begin{array}{l}\text { Top } \\
\text { Management } \\
\text { Support }\end{array}$ & 17.135 & 17.135 \\
\hline 2 & $\begin{array}{l}\text { Goal \& } \\
\text { Objective } \\
\text { User } \\
\text { Knowledge }\end{array}$ & 13.499 & 30.634
\end{tabular}

Table showing the percentage of variance and the various CSF after analysis

This finding is significant for ERP vendors and more so in present economic scenario where the SME's have to be convinced regarding the return on their investment as a result of their investment in ERP packages. The participation of external consultants and adequate vendor support even after implementation are other crucial factors underlying successful implementations of ERP projects in SMEs.Users in these SME's prefer a handholding approach even after the users have been provided substantial training. The management in SME's tend to ignore this aspect as they consider these as an additional cost to their already incurred cost of purchasing the package. Management can negotiate with the vendors and arrive at an acceptable price for engaging external consultants and also provide their users with adequate training. In context to Indian SME segment it has been observed that the management generally tend to expect a decent return on investment in a 1-1.5 years after implementation and are generally reluctant to spend more on user training apart from what is provide by the vendors as is part of the deal( and is bare minimum !). Another feature that has been observed is 
that the IS infrastructure in such organisations are not very structured and hence inadvertently problem arises during and after implementation. In such scenario the management should intervene in the form of defining a work group (consisting of functional as well as technical people and external consultants, if possible) but generally this is not the case. The users associated with the IS department are left to defend for themselves even though the problem may be more of functional in nature rather than technical.

\section{Conclusion}

ERP Investments has been top IT spending priorities for SME's off late. Any information system implementation is a complex task and hence complex ERP environments present several challenges. Most business organizations which are SME in nature have complex ERP environments consisting of customized packages from multiple vendors, as well as an array of internally developed software that must integrate with the packages. And there is also a perpetual gap between package functionality and business needs. Companies address the gap by customizing the software, building extensions, or buying specialized, best of- breed packages. These remedies limit flexibility as business needs evolve and increase implementation and integration costs - Customization and integration comprise about a third of the cost of the initial implementation.

Customization is compounded by an unwillingness to change business processes. Alignment of business processes to ERP software, rather than modifying the software, has proven to be a success factor for many implementations. At least as many, however, took advantage of vendor-provided tools to adapt the software to the nuances of their business. This often raised implementation and support costs well beyond the business value of the software changes.ERP environments are costly to maintain. Companies spend between $20 \%$ and $33 \%$ of their implementation costs every year on maintaining the systems. Escalating vendor maintenance fees along with mandatory upgrades contribute to higher costs of ownership. Customization increases ownership costs, as the applications become more difficult to upgrade.

The findings holds significance for any organization in the small and medium scale sector which wishes to leverage the benefits of integration of business processes by implementing an ERP system in their organization. Literature shows many instances of ERP implementation which failed to deliver the business returns and in some cases the entire project implementation cost has been a sunk cost for the organization getting no return on their investment. This outcome much more acute in case of SME because of their inherent peculiarities.

\section{References:}

1. Butler, T. and Pyke, A. (2003). Examining the influence of ERP systems on firm-specific knowledge and core capabilities: a case study of SAP implementation and use. In Proceedings of the Eleventh European Conference on Information Systems (Ciborra CU, Mercurio R, de Marco M, Martinez M, Carignani A eds.), Naples, Italy.

2. Beck, R., Weitzel, T. and König, W. (2002). Promises and pitfalls of SME integration. In 
Proceedings of 15th Bled Electronic Commerce Conference: e-Reality: Constructing the e-Economy, Bled, Slovenia

3. Caruso, A. and Marchiori, M. (2003). The Adoption of Information Systems in SME's: Organizational Issues and Success Factors. In Proceedings of the 11th European Conference on Information Systems (Ciborra C.U., Mercurio R., de Marco M., Martinez M., Carignani A. eds.), Naples, Italy.

4. Chan, R. (1999), “Knowledge management for implementing ERP in SME's”, paper presented at the 3rd Annual SAP Asia Pacific, Institute of Higher Learning Forum, and Singapore.

5. Costa, G. and Gianecchini, M. (2006). Tecnologia, cambiamento organization e competitività Il ruolo dei sistemi informativi integrati. Paper presented to the workshop WOA 2006 Organizzazione, Regolazione e Competitivita, Fisciano, Salerno, Italy, February 2-3.

6.Compagno, C., Visintin, F. and Pittino D. (2004). ICT e cambiamento organization nelle piccole emedie imprese. In D’Atri, A. (a cura di), Innovazione organizzative e tecnologie innovative, Etas,Milan, p. 45-55.

7.Equey, C. and Rey, A. (2004). La mise en place d'une solution de gestion moderne (ERP/PGI), quells enjeux pour une PME/PMI. Étude réalisée par la Haute École de Gestion de Genève août 2004, available at: http://www.hesge.ch/heg/prestations_recherche/doc/ce_ERP.pdf

8.El Amrani, R., Rowe, F., Bidan, M., Geffroy-Maronnat, B. and Marciniak, R. (2003). ERP Implementation and change: towards a cross- functional view. In Proceedings of the $11^{\text {th }}$ European Conference on Information Systems (Ciborra C.U., Mercurio R., de Marco M., Martinez M., Carignani A. eds.), Naples, Italy

9.Esteves, J. and Pastor, J. (2001). Enterprise resource planning systems research: an annotated bibliography, Communications of AIS 7 (8), 2001, p. 1-51.

10.Kemppainen, I. (2004). Change management perspectives in an ERP implementation. In Proceedings of the Twelfth European Conference on Information Systems (Leino T, Saarinen T, Klein S eds.),Turku, Finland.

11.Laframboise, K. (2002). Business performance and enterprise resource planning. In Proceedings of the Tenth European Conference on Information Systems (Wrycza S ed.), Gdansk, Poland.

12. Levy, M. and Powell, P. (2000), "Information systems strategy for small- medium-sized enterprises: an organizational perspective”, Journal of Strategic Information Systems, Vol. 9 No. 1, pp. 63-84.

13. Magnusson, J., Nilsson, A. and Carlsson, F. (2004). Forecasting ERP implementation success - Towards a grounded framework. In Proceedings of the Twelfth European Conference on Information Systems (Leino T, Saarinen T, Klein S eds.), Turku, Finland.

14.Møller, C., Kræmmergaard, P., Rikhardsson, P., Møller, P., Jensen, T.N. and Due, L. (2004). A Comprehensive ERP Bibliography - 2000-2004. IFI Working Paper no. 129, ISSN no. 1398-067, Aarhus School of Business, Denmark.

15.Nandhakumar, J., Talvinen, J.M. and Rossi, M. (2004). ERP revelations: the dynamics of contextual forces of ERP implementation. In Proceedings of the Twelfth European Conference on Information Systems (Leino T, Saarinen T, Klein S eds.), Turku, Finland. 
16.Ravarini, A., Tagliavini, M., Pigni, F. and Sciuto, D. (2000). A Frame-work for Evaluating ERP Acquisition within SMEs. In Proceedings of the AIM International Conference. Montpellier, France, pp. 1-11.

17.Rao, S.S. (2000), “Enterprise resource planning: business needs and technologies", Industrial Management \& Data Systems, Vol. 100 No. 2, pp. 81-8.

18.Schubert, P. and Leimstoll, U. (2004). Personalization of E-Commerce Applications in SME's: Conclusions from an Empirical Study in Switzerland. In Journal of Electronic Commerce in Organizations, 2 (3), July-Sept, p. 21-39.

19. Schubert, P. (2003). Personalizing E-Commerce Applications in SME's. In Proceedings of the Ninth Americas Conference on Information Systems (AMCIS)

20.Tagliavini, M., Faverio, P., Ravarini, A., Pigni, F. and Buonanno, G. (2002), "Exploring the use of ERP systems by SME's", in Callaos, N. (Ed.), SCI 2002: 6th World Multiconference on Systemics, Cybernetics and Informatics, Orlando, FL.

21.Westrup, C. and Knight, F. (2000). Consultants and Enterprise Resource Planning (ERP) Systems. In Proceedings of the Eighth European Conference on Information Systems (Hansen HR, Bichler M, Mahrer H eds.), Wien, Austria. 